\title{
PENDEKATAN BIONOMI DALAM PENGELOLAAN KAWASAN KONSERVASI LAUT KABUPATEN RAJA AMPAT, PROVINSI PAPUA BARAT
}

\section{The Management of Marine Protected Area of Raja Ampat Regency, West Papua Province Through Bioeconomic Model Approach}

\author{
Oleh: \\ Eny B. S. Haryani1 ${ }^{*}$, Akhmad Fauzi², dan Daniel R. Monintja ${ }^{3}$ \\ ${ }^{1}$ Direktorat Jenderal Kelautan Pesisir dan Pulau Kecil, Kementerian Kelautan dan Perikanan RI, \\ Jl MT Haryono Kav. 52-53 Jakarta Selatan \\ 2 Departemen Ekonomi Sumber Daya dan Lingkungan, FEM, IPB, \\ Wing Rektorat lt. 3 Kampus IPB Darmaga - Bogor 16680 \\ ${ }^{3}$ Departemen Pemanfaatan Sumber Daya Perikanan, FPIK, IPB, Jl. Lingkar Kampus, Darmaga - Bogor 16680
}

*Korespondensi: enyharyani@yahoo.com

Diterima: 7 Desember 2010; Disetujui: 26 Maret 2010

\begin{abstract}
Raja Ampat Regency in West Papua Province has abundance natural fishery resources. Marine Protected Area (MPA) has been established in marine areas of Raja Ampat Regency. To better manage of MPA is required with measureable parameters and clear indicators. To decide the indicator can be conducted by bioeconomic model approach. The results of research show that the establishment of MPA will increase harvest level and revenue. But "bigger is better" could'nt be adopted for the development of MPA. There is an optimal MPA size will contribute for increasing yields and revenue and can reduce the level of effort.
\end{abstract}

Key words: bionomic model, marine protected area, measureable indicators, Raja Ampat-West Papua

\section{ABSTRAK}

Kabupaten Raja Ampat, Provinsi Papua Barat, memiliki kekayaan sumber daya ikan (SDI) yang berlimpah. Kawasan Konservasi Laut (KKL) telah dikembangkan di kawasan perairan Kabupaten Raja Ampat. Parameter yang terukur dan indikator yang jelas diperlukan untuk pengelolaan yang lebih baik. Penentuan indikator dapat dilakukan dengan pendekatan model bionomi. Hasil penelitian memperlihatkan, bahwa penerapan KKL dapat meningkatkan produksi dan keuntungan ekonomi. Namun "bigger is better" dalam kasus KKL tidak berlaku untuk seluruh kasus KKL, artinya ada luasan optimal untuk KKL yang menjamin terjadinya keuntungan ekonomi.

Kata kunci: model bionomi, kawasan konservasi laut, indikator terukur, Raja Ampat- Papua Barat

\section{PENDAHULUAN}

Kabupaten Raja Ampat sebagai kabupaten bahari, memiliki sekitar $85 \%$ wilayah berupa laut, dan $80 \%$ masyarakatnya berprofesi sebagai nelayan. Pengembangan Kawasan Kon- servasi Laut $(\mathrm{KKL})$ sudah sejak lama dilakukan dan terdiri dari Kawasan Konservasi Laut Daerah (KKLD) dan Suaka Margasatwa Laut (SML), yang luasnya mencapai lebih dari 1 juta hektar (DKP Kabupaten Raja Ampat, 2006 dan 2008). 
Sesuai Peraturan Pemerintah No. 60 tahun 2007 tentang Konservasi Sumber daya Ikan (KSDI), maka KKL merupakan kawasan perairan laut yang dilindungi, dikelola dengan sistem zonasi, untuk mewujudkan pengelolaan sumber daya ikan (SDI) dan lingkungannya secara berkelanjutan. Namun sebagai instrumen untuk menjamin perikanan berkelanjutan, $\mathrm{KKL}$ Kabupaten Raja Ampat perlu dikelola dengan tepat agar bermanfaat bagi kesejahteraan masyarakat.

Kawasan Konservasi Laut Kabupaten Raja Ampat, dengan kondisi ekosistemnya yang didominasi gugus pulau kecil, yang relatif masih alami dan terjaga, memerlukan upaya pengelolaan yang terukur dan memiliki indikator yang jelas. Variabel-variabel tersebut sangat kompleks yang didekati dengan pemodelan bionomi yang dapat menyederhanakan variabel-variabel kompleks. Fokus analisis pada penelitian ini adalah perikanan tangkap untuk jenis-jenis ikan karang atau ikan demersal. Oleh sebab itu penelitian dengan pendekatan pemodelan bionomi ini dilakukan, untuk menganalisis performance baseline perikanan dalam skenario KKL. Indicator performance diukur melalui perhitungan input dan output, serta manfaat ekonomi yang optimal dengan adanya KKL.

\section{METODE PENELITIAN}

\section{Waktu Penelitian}

Penelitian dilakukan bulan September 2008 sampai dengan September 2009 di KKL Kabupaten Raja Ampat, Provinsi Papua Barat, dengan posisi geografis dan peta KKL seperti terlihat pada Gambar 1.

Pertimbangan pemilihan lokasi karena KKL Kabupaten Raja Ampat memiliki wilayah yang cukup luas. Sebagian besar luasannya merupakan $\mathrm{KKL}$ yang masih baru, terdiri atas gugusan pulau kecil, penetapannya oleh Menteri Kelautan dan Perikanan di lakukan pada tanggal 12 Mei 2007 (DKP Kabupaten Raja Ampat, 2008). Pengembangan KKL Kabupaten Raja Ampat ini masih sangat prematur, sehingga management plan dan perangkat pengelolaan lainnya belum ada atau masih dalam taraf penyusunan. Kondisi sumber daya kelautan dan perikanannya juga masih baik, dengan keanekaragaman hayati relatif tinggi. KKL Kabupaten Raja Ampat merepresentasikan sistem pengembangan KKL dibawah pembinaan Departemen Kelautan dan Perikanan, yang tujuan utama penetapannya untuk menjamin pengelolaan perikanan berkelanjutan.

\section{Metode Pengumpulan Data}

Penelitian ini dibatasi hanya pada analisis bionomi yang menyangkut sumber daya perikanan dan interaksi antara perikanan tangkap dan KKL. Lokasi penelitian dilakukan di 6 (enam) desa di Distrik Waigeo Selatan, yaitu di Desa Yanbekwan, Desa Sawingrai, Desa Yen Buba, Desa Kapisawur, Desa Saporkren, dan Desa Saonek. SDI yang dianalisis hanya perikanan tangkap untuk ikan karang atau demersal untuk spesies tertentu yang didaratkan melalui perahu di Pusat Pendaratan Ikan (PPI) Sorong.

Metode pengambilan sampel/responden yang digunakan adalah purposive sampling. Data yang dikumpulkan dalam penelitian ini bersumber dari data primer dan data sekunder. Data primer diperoleh melalui wawancara dan pengisian kuesioner terhadap responden, yang terdiri dari nelayan sampel, tokoh masyarakat, pengelola usaha perikanan, pengelola wisata, pengelola $\mathrm{KKL}$, pemerintah daerah dan wisatawan. Data primer yang digunakan meliputi: 1) Data biaya operasional penangkapan ikan yang terdiri dari biaya bahan bakar minyak (solar), oli, es balok/bungkus, biaya konsumsi (makanan dan rokok) selama melaut dan umpan; 2) Data biaya pemeliharaan armada tangkap kapal/perahu penangkap ikan; 3) Data harga ikan dan penghasilan per trip dari kapal perahu yang digunakan; 4) Persepsi responden (nelayan, pengelola KKL, tokoh masyarakat dan Pemda) tentang keberadaan KKL di lokasi penelitian; 5) Data usaha perikanan budidaya, wisata bahari, pemanfaatan terumbu karang, mangrove dan lamun; dan 6) Kondisi sosial, ekonomi, dan budaya masyarakat di lokasi penelitian.

Data sekunder yang diperlukan bersifat urut waktu (time series), meliputi data produksi (landing) ikan karang dan input yang digunakan (effort), harga per unit output (harga ikan per kg per periode), indeks harga konsumen (consumers price index) dan data penunjang lainnya. Data sekunder ini diperoleh baik dari penelitian dinas/instansi/lembaga yang terkait dengan pengelolaan dan penelitian perikanan di lokasi penelitian. Dinas/instansi/lembaga itu meliputi: Biro Pusat Statistik (BPS), Dinas Perikanan dan Kelautan, Dinas Lingkungan Hidup, Dinas Kehutanan, BAPPEDA, Pusat Pendaratan Ikan, Tempat Pelelangan Ikan, Lembaga Swadaya Masyarakat lokal dan pusat, serta institusi lain terkait. 


\section{Kawasan Konservasi Kabupaten Raja Ampat}

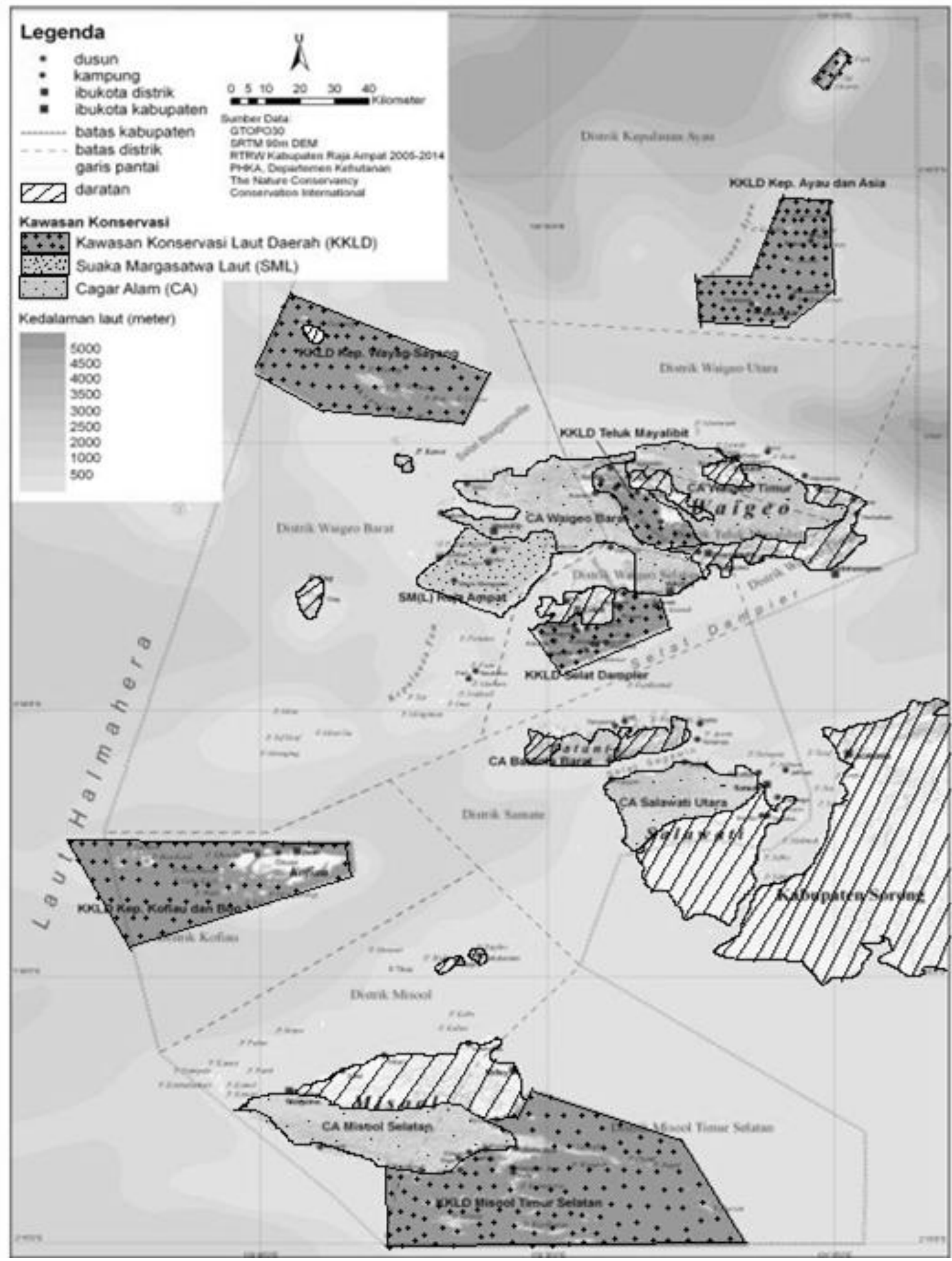

Gambar 1 Posisi geografis dan peta KKL Kabupaten Raja Ampat. (DKP Kabupaten Raja Ampat, 2008) 


\section{Metode Analisis Data}

Analisis ekonomi kawasan $\mathrm{KKL}$ dengan pendekatan bionomi menggunakan model fungsi pertumbuhan ikan secara logistic, yang akan dimodifikasi untuk perikanan tangkap jenis-jenis ikan karang atau demersal, dalam kondisi diberlakukannya KKL. Jika diasumsikan fungsi pertumbuhan biomasa di kawasan konservasi mengikuti fungsi logistic (Fauzi dan Anna, 2005; Anna, 2006):

$$
\frac{d x}{d t}=r x\left(1-\frac{x}{K}\right)
$$

Keterangan:

$r=$ laju pertumbuhan intrinsik

$x=$ biomasa

$K=$ kapasitas daya dukung lingkungan

Fungsi penangkapan diasumsikan bersifat Cobb-Douglass:

$$
h=q x E
$$

Keterangan:

$h=$ produksi tangkap

$q=$ kemampuan daya tangkap

$E$ =upaya

Dalam kondisi diterapkan KKL, fungsi penangkapan akan berubah menjadi:

$$
h=(1-\gamma) q x E \text {. }
$$

dimana $\gamma=$ prosentase luasan kawasan KKL.

Adanya persamaan (3), maka dinamika stok pada persamaan (1) akan berubah menjadi:

$$
\frac{d x}{d t}=r x\left(1-\frac{x}{K}\right)-(1-\gamma) q x E \text {.. }
$$

Dengan mengasumsikan kondisi dalam keseimbangan, maka solusi dari persamaan (4) akan menghasilkan variabel $x$ sebagai fungsi dari parameter biofisik dan variabel $E$. Hasil pemecahan ini jika disubstitusikan pada persamaan (3) akan menghasilkan persamaan yield effort yang mengandung parameter $\mathrm{KKL}$, sebagai berikut (Fauzi dan Anna, 2005; Anna, 2006):

$$
h=q E K\left(1-\frac{(1-\gamma)}{r} q E\right)
$$

Rente ekonomi yang dihasilkan dari penangkapan dalam kondisi sustainable di atas, adalah:

$$
\pi=p q E K\left(1-\frac{(1-\gamma)}{r} q E\right)-c E
$$

Keterangan:

$\mathrm{p}=$ harga ikan per $\mathrm{kg}$

$\mathrm{C}=$ biaya penangkapan per unit upaya (effort)

Untuk mengetahui tingkat upaya yang optimal, maka rente di atas diturunkan terhadap upaya sebagai berikut:

$$
\mathrm{E}^{*}=\partial \pi / \partial \mathrm{E}=\mathrm{pqK}-2 \mathrm{pqK}\left(\frac{(1-\gamma)}{\mathrm{r}} \mathrm{q}\right) \mathrm{E}-\mathrm{c}=0 \ldots
$$

sehingga dihasilkan:

$$
E^{*}=\left(\frac{(p q K-c) r}{2 p q K(1-\gamma)}\right)
$$

Menurut Sanchirico dan Wilen (2001), perhitungan model dapat dilakukan dengan mensimulasikan luas wilayah konservasi ke dalam perhitungan. Model bionomi KKL ini dilakukan pada beberapa skenario ukuran $\mathrm{KKL}$, yaitu $10 \%, 20 \%, 30 \%$, 40\%, 50\%, dan $60 \%$ relatif terhadap luas total area penangkapan ikan. $\mathrm{Pa}$ rameter ekonomi yaitu harga dan biaya, diasumsikan konstan pada model ini, sedangkan fungsi permintaan diasumsikan perfectly inelastic.

\section{HASIL DAN PEMBAHASAN}

Prinsip KKL adalah spill over effect atau dampak limpahan, dimana pada kawasan yang dilindungi, stok ikan akan tumbuh dengan baik dan limpahan dari pertumbuhan ini akan mengalir ke wilayah di luar kawasan, yang dapat dimanfaatkan secara berkelanjutan tanpa mengurangi sumber pertumbuhan di daerah yang dilindungi (Fauzi dan Anna, 2005). KKL memiliki banyak manfaat signifikan yang akan membantu pengelolaan SDI dalam jangka panjang. Wilayah konservasi juga merupakan sebuah solusi sederhana yang dapat dilakukan untuk mengelola keberlanjutan usaha perikanan (Roberts, M.C and N.V.C. Polunin. 1993). Peraturan Pemerintah No. 60 Tahun 2007 tentang KSDI menjelaskan bahwa, kawasan konservasi laut dimaksudkan untuk mewujudkan pengelolaan SDI dan lingkungan berkelanjutan.

Pengelolaan sumber daya ikan karang sebagai ikan demersal pada kondisi dengan 
KKL, dengan luasan KKL 0,1 (10\%) relatif terhadap luas total area penangkapan ikan, diperoleh jumlah effort sebanyak 38,07 trip per minggu. Jumlah tangkapan yang diperoleh 6,3 ton per minggu, dengan rente sumber daya sebanyak Rp 36,52 juta rupiah per minggu. Luasan KKL 0,2 (20\%), diperoleh effort sebesar 36,84 trip per minggu dan nilai rente yang diperoleh lebih kecil yaitu Rp. 30,39 juta rupiah per minggu. Begitu juga dengan luasan $\mathrm{KKL}$ sampai dengan $0,6(60 \%)$, jumlah effort menurun menjadi 25,77 trip per minggu, dengan rente sebesar Rp. 7,39 juta rupiah per minggu (Tabel 1).

Tingkat effort pada luasan KKL 0,1 (10\%) jauh lebih tinggi dibandingkan dengan luasan $0,2(20 \%)$ yaitu sebanyak 38,07 trip per minggu, sedangkan untuk luasan $0,2(20 \%)$ sebanyak 36,84 trip per minggu. Tingkat effort yang tinggi, akan menyebabkan produksi tinggi pula, yang akhirnya akan berimplikasi terhadap ting- ginya rente yang diterima nelayan. Tabel 1 memperlihatkan bahwa rente terus mengalami penurunan seiring dengan penurunan tingkat produksi dan jumlah effort, meskipun luasan KKL terus meningkat. Gambar 2, Gambar 3 dan Gambar 4 memperlihatkan perbandingan antara produksi aktual, effort aktual, dan rente dalam pengelolaan ikan karang sebagai ikan demersal dengan adanya pengaruh $\mathrm{KKL}$ di Kabupaten Raja Ampat.

Gambar 2 menunjukkan bahwa $\mathrm{KKL}$ telah memberikan manfaat yang berarti, yaitu peningkatan produksi perikanan sebesar $59,22 \%$ dibandingkan sebelum adanya KKL. Halpern (2003) dalam Fauzi A dan Anna S (2005) menyatakan bahwa secara rata-rata $\mathrm{KKL}$ telah meningkatkan kelimpahan (abundance) sebesar 2 (dua) kali lipat, sementara biomasa ikan dan keanekaragaman hayati meningkat 3 (tiga) kali lipat. Peningkatan kelimpahan dan biomasa ini juga mengakibatkan pe-

Tabel 1 Hasil analisis bionomi tanpa KKL dan dengan KKL dalam pengelolaan SDI karang atau demersal di Kabupaten Raja Ampat

\begin{tabular}{ccccccc}
\hline $\begin{array}{c}\boldsymbol{\sigma} \text { Luasan KKL } \\
\text { (simulasi luasan } \\
\text { KKL dari total } \\
\text { kawasan, dalam } \\
\% \text { ) }\end{array}$ & $\begin{array}{c}\boldsymbol{h} \text { Tanpa } \\
\text { KKL } \\
\text { (ton per } \\
\text { minggu) }\end{array}$ & $\begin{array}{c}\boldsymbol{h} \text { KKL } \\
\text { (ton per } \\
\text { minggu) }\end{array}$ & $\begin{array}{c}\text { E Tanpa } \\
\text { KKL } \\
\text { (trip per } \\
\text { minggu) }\end{array}$ & $\begin{array}{c}E \text { KKL } \\
\text { (trip per } \\
\text { minggu) }\end{array}$ & $\begin{array}{c}\boldsymbol{\pi} \text { Tanpa } \\
\text { KKL } \\
\text { (juta } \\
\text { rupiah } \\
\text { per } \\
\text { minggu) }\end{array}$ & $\begin{array}{c}\boldsymbol{m} \text { KKL } \\
\text { (juta } \\
\text { rupiah } \\
\text { per } \\
\text { minggu) }\end{array}$ \\
\hline 10 & 3,50 & 6,30 & 52,43 & 38,07 & 8,03 & 36,52 \\
20 & 3,50 & 6,23 & 52,43 & 36,84 & 8,03 & 30,39 \\
30 & 3,50 & 6,12 & 52,43 & 35,26 & 8,03 & 24,34 \\
40 & 3,50 & 5,95 & 52,43 & 33,15 & 8,03 & 18,43 \\
50 & 3,50 & 5,68 & 52,43 & 30,20 & 8,03 & 12,72 \\
60 & 3,50 & 5,17 & 52,43 & 25,77 & 8,03 & 7,39 \\
\hline
\end{tabular}

Sumber: data hasil olahan

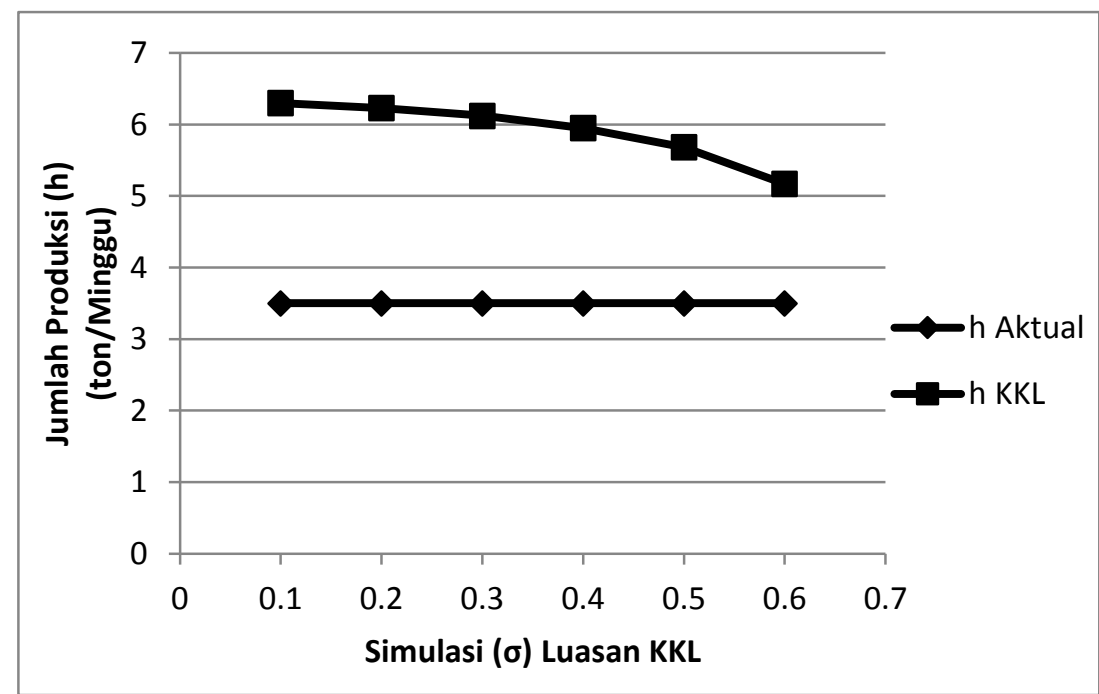

Gambar 2 Perkembangan produksi $(h)$ tanpa KKL (aktual) dan dengan KKL, dengan luasan KKL $10-60 \%$ dari total kawasan perikanan tangkap. 
ningkatan produksi perikanan (jumlah tangkap dan rasio tangkap per unit effort atau CPUE). Terdapat bukti yang kuat, bahwa melindungi daerah dari penangkapan ikan membuat bertambahnya jumlah, besarnya ukuran dan biomasa dari jenis SDI yang dieksploitasi. KKL sering dikatakan hanya berlaku untuk ekosistem terumbu karang. Namun kenyataannya, metode ini sudah berhasil diterapkan pada berbagai ekosistem laut, di daerah tropis maupun subtropis. KKL dapat dikatakan sebagai suatu alat pengelolaan SDI berkelanjutan yang bersifat global (Roberts and Hawkins, 2000).

Gambar 2 memperlihatkan bahwa, tingkat produksi aktual dengan adanya KKL lebih besar dibandingkan dengan produksi aktual tanpa KKL. Tetapi produksi aktual dengan adanya $\mathrm{KKL}$ terus mengalami penurunan seiring dengan bertambahnya luasan KKL. Kondisi ini dipengaruhi oleh berkurangnya jumlah alat tangkap, sekaligus turunnya upaya penangkapan (effort). Dengan demikian, semakin luas kawasan KKL akan mengakibatkan penurunan terhadap produksi aktual.

Gambar 3 menunjukkan perbandingan antara upaya (effort) aktual dengan KKL, dengan effort aktual tanpa KKL. Effort aktual dengan KKL berada di bawah effort aktual tanpa $\mathrm{KKL}$. Effort aktual dengan KKL cenderung mengalami penurunan seiring dengan bertambahnya luasan KKL. Semakin luas kawasan $\mathrm{KKL}$ menyebabkan penurunan terhadap effort di kawasan dengan KKL. Berbeda halnya dengan effort aktual tanpa $\mathrm{KKL}$, bahwa effort aktual tanpa $\mathrm{KKL}$ cenderung stabil meskipun terjadi penambahan luasan $\mathrm{KKL}$, artinya tidak mengalami penurunan maupun peningkatan yang signifikan. Kondisi ini bila tidak dikendalikan akan menyebabkan terjadinya degradasi SDI karang sebagai ikan demersal di perairan Kabupaten Raja Ampat. Peran KKL sangat penting sebagai pengendali effort sehingga degradasi SDI dapat dikendalikan. Lebih jelas perkembangan effort dapat dilihat pada

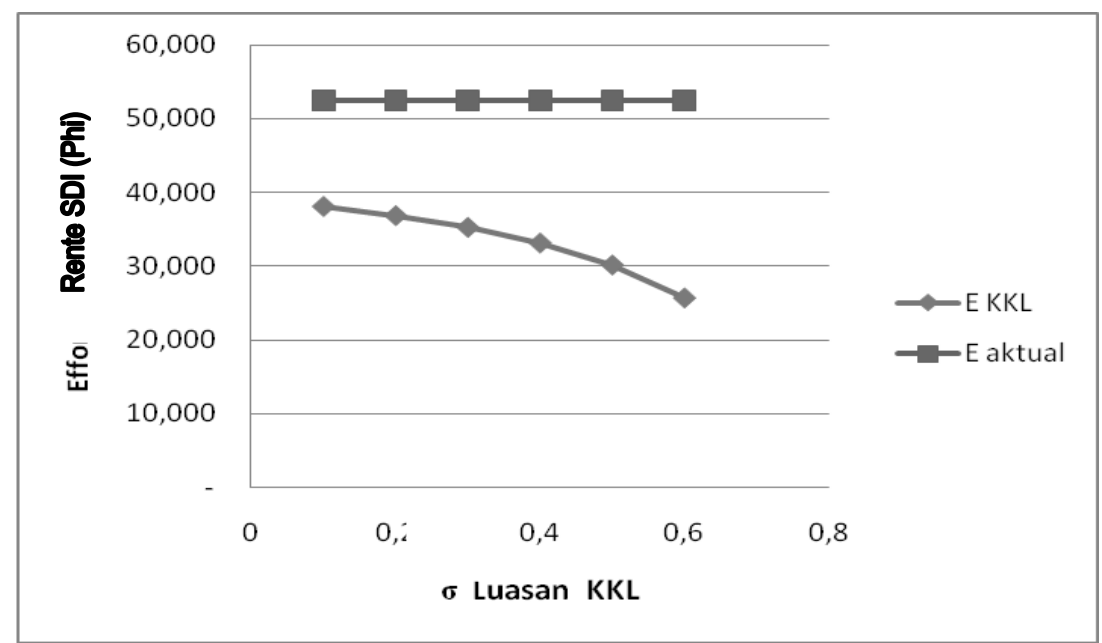

Gambar 3 Perbandingan effort aktual dengan KKL dan effort aktual tanpa KKL.

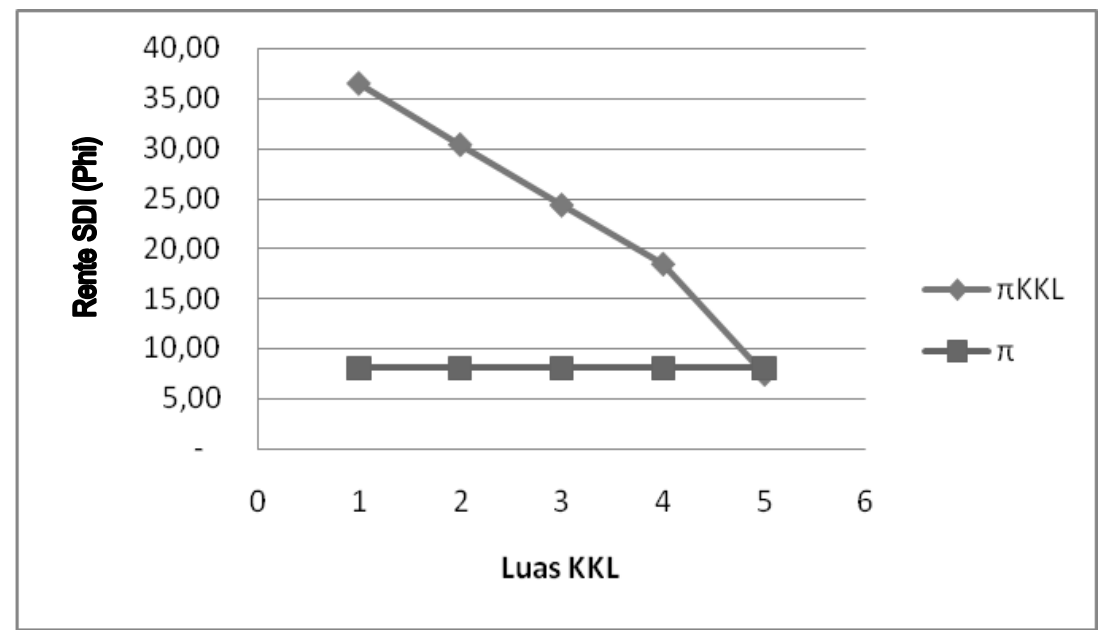

Gambar 4 Hubungan antara KKL dan rente SDI atau manfaat ekonomi. 
Gambar 3 yang menunjukkan adanya $\mathrm{KKL}$ terjadi penurunan effort yang sangat berarti, dari kondisi sebelum adanya KKL.

Penggunaan alat tangkap memperlihatkan tingkat effort aktual tertinggi pada luasan $0,1(10 \%)$ yaitu berada pada tingkat effort sebesar 38,07 trip per minggu. Gambar 3 menunjukkan bahwa tingkat effort aktual dengan $\mathrm{KKL}$ menunjukkan trend menurun hingga tingkat 25,77 trip per minggu.

Rente yang diperoleh dengan $\mathrm{KKL}$ cenderung mengalami penurunan seiring dengan penambahan luasan KKL (Gambar 4). Rente yang diperoleh pada luasan KKL 0,1 (10\%) sebesar Rp 36,52 juta rupiah per minggu, rente yang diperoleh dengan luasan KKL 0,2 (20\%), menurun menjadi Rp 30,39 juta rupiah per minggu. Rente dengan adanya KKL terus mengalami penurunan, disebabkan karena produksi dan effort yang terus menurun. Semakin luas kawasan $\mathrm{KKL}$, maka rente yang diperoleh akan semakin kecil.

Gambar 4 memperlihatkan bahwa, rente yang diperoleh tanpa $\mathrm{KKL}$ cenderung tidak terpengaruh dengan penambahan luasan $\mathrm{KKL}$. Jika luasan ditambah menjadi 0,6 (60\%), maka rente yang diperoleh dengan $\mathrm{KKL}$ jauh lebih kecil dibandingkan dengan rente yang diperoleh tanpa KKL. Hubungan antara luasan KKL dengan manfaat ekonomi yang diperoleh dapat dilihat pada Gambar 4. Penambahan luasan KKL di Kabupaten Raja Ampat, akan meningkatkan manfaat ekonomi pada kisaran tertentu. Penambahan luasan KKL di bawah 0,6 (60\%) masih dapat meningkatkan manfaat ekonomi, yaitu masih berada diatas manfaat ekonomi aktual tanpa KKL. Melewati kisaran tersebut, semakin luas $\mathrm{KKL}$ akan semakin kecil manfaat ekonomi yang diperoleh, yaitu di bawah manfaat ekonomi aktual tanpa KKL (Gambar 4).

Hal ini senada dengan prediksi yang dikemukakan oleh Arnason (2000) yang diacu dalam Fauzi dan Anna (2005), mengenai hubungan antara luasan KKL dengan manfaat ekonomi yang berbentuk concave (cembung). Hasil studi juga membuktikan bahwa "bigger is better" dalam kasus KKL tidak berlaku untuk seluruh kasus KKL karena di beberapa wilayah KKL menunjukkan tidak optimalnya pengelolaan dan terjadinya inefesiensi dalam pengelolaan KKL seiring bertambahnya wilayah konservasi (Fauzi, A. and E. Buchary, 2002).

Senada yang disampaikan oleh Armstrong and Reithes (2001), bahwa KKL pada ukuran luas tertentu dapat dimanfaatkan sebagai alat pengelolaan perikanan yang efektif, dibandingkan sistem kuota tradisional. Ikan karang berkumpul di tempat-tempat tertentu untuk memijah. Adanya KKL dapat membantu melindungi tempat-tempat pemijahan ini, yang sangat rentan terhadap kegiatan penangkapan ikan, baik secara tradisional maupun komersial (Fauzi, 2001). Keberadaan KKL di tempat-tempat pemijahan yang penting, dapat dijadikan sebagai dasar dalam menentukan lokasi KKL. Pada wilayah KKL multiguna yang luas dan besar, lokasi pemijahan bisa ditentukan sebagai wilayah terlarang untuk penangkapan (Johannes, 1998).

Hasil pemecahan analitik dengan menggunakan program MAPLE 11, diperoleh kurva berbagai rezim pengelolaan SDI karang dengan unit armada tangkap perahu. Gambar 5 sampai Gambar 9 menunjukkan bahwa dengan $\mathrm{KKL}$, kurva yield mengalami peningkatan yang cukup signifikan. Hal ini disebabkan oleh me-
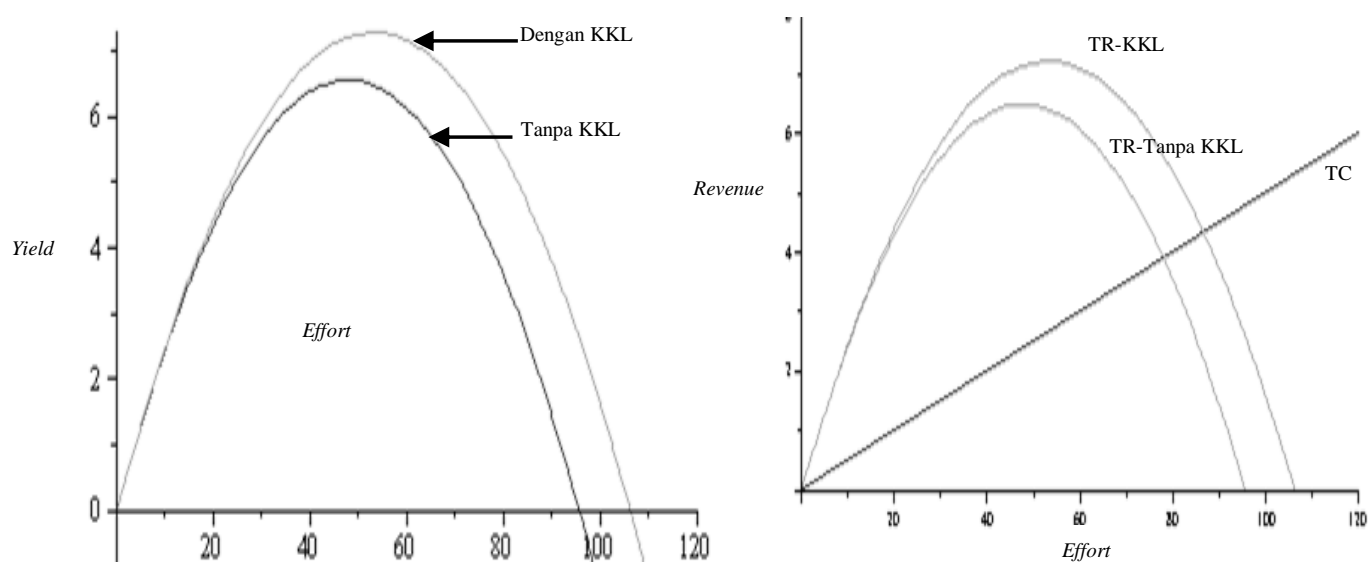

Gambar 5 Kurva yield-effort dan total revenue dengan luasan KKL ( $\sigma=10 \%$ ). 

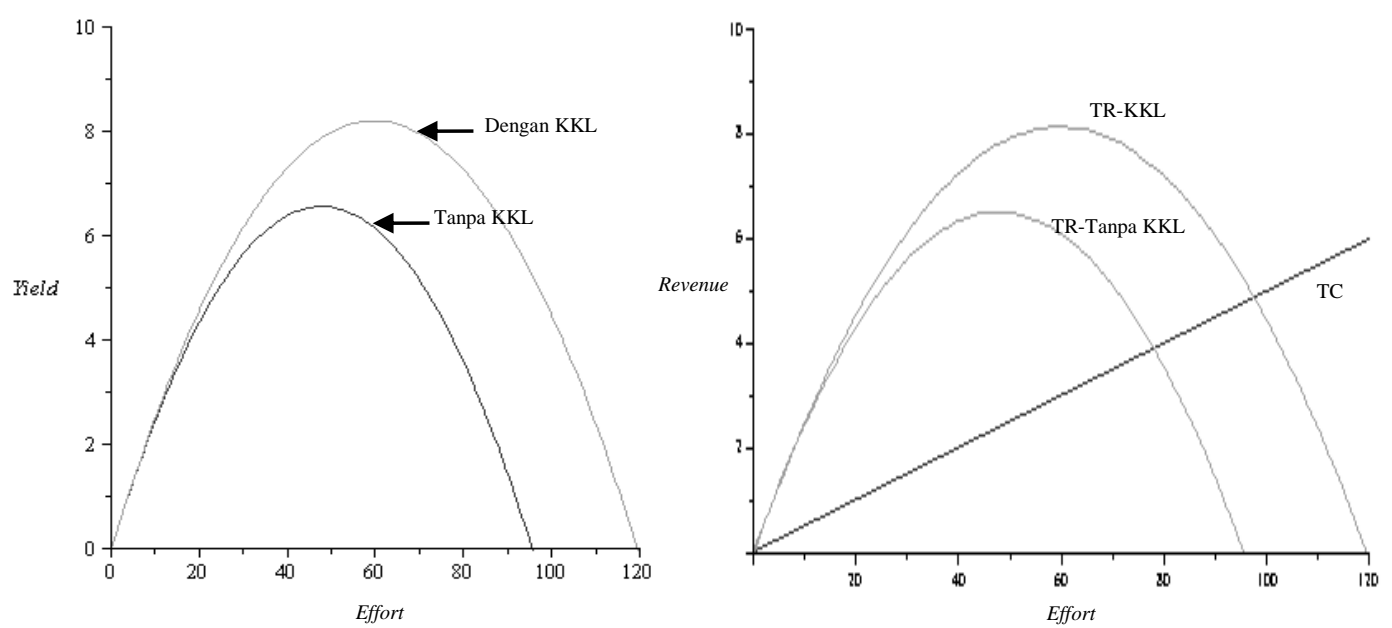

Gambar 6 Kurva yield-effort dan total revenue dengan luasan KKL $(\sigma=20 \%)$.
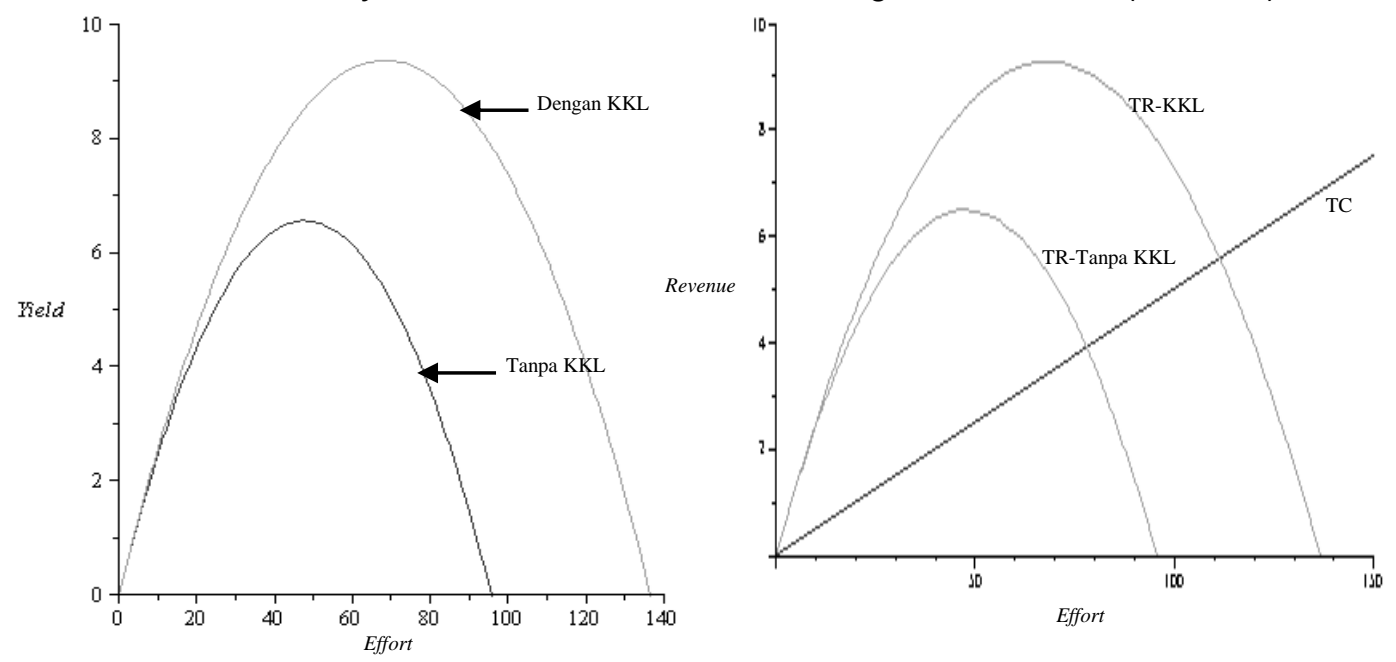

Gambar 7 Kurva yield-effort dan total revenue dengan luasan KKL $(\sigma=30 \%)$.
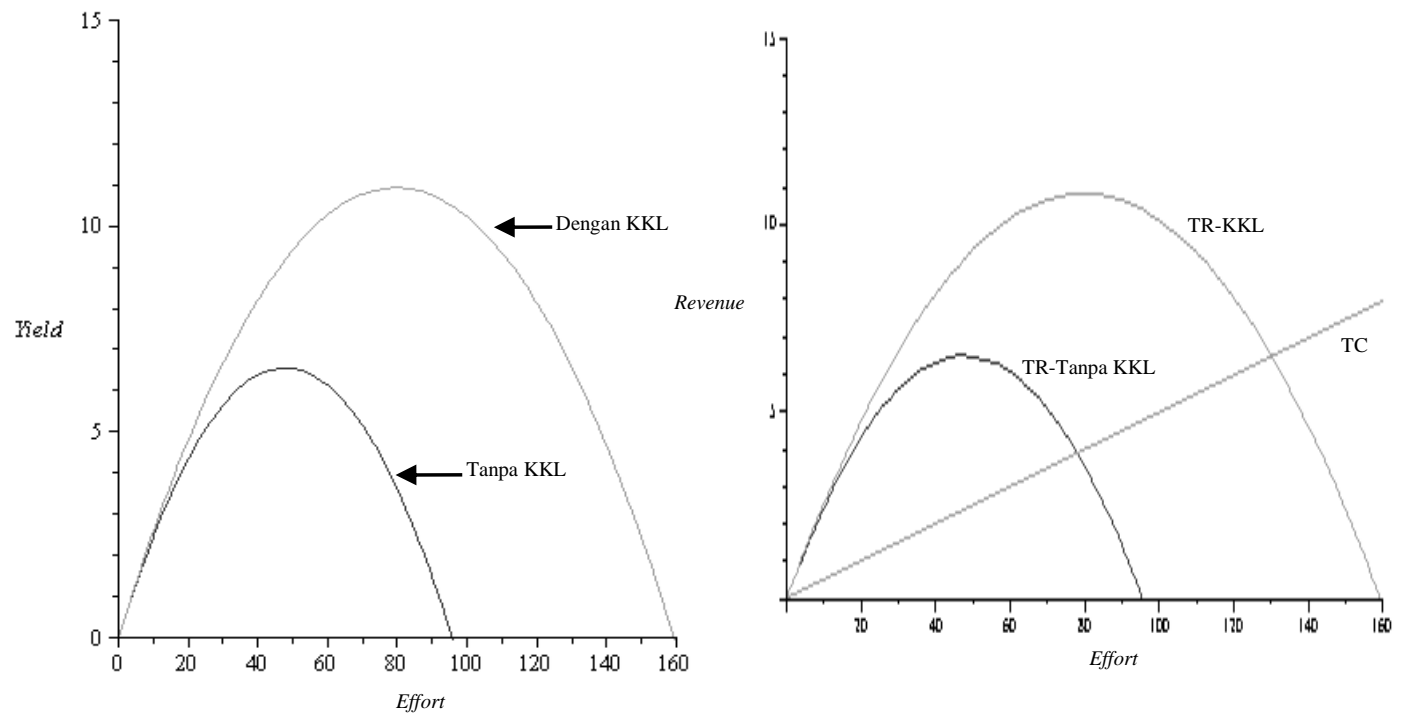

Gambar 8 Kurva yield-effort dan total revenue dengan luasan KKL $(\sigma=40 \%)$. 

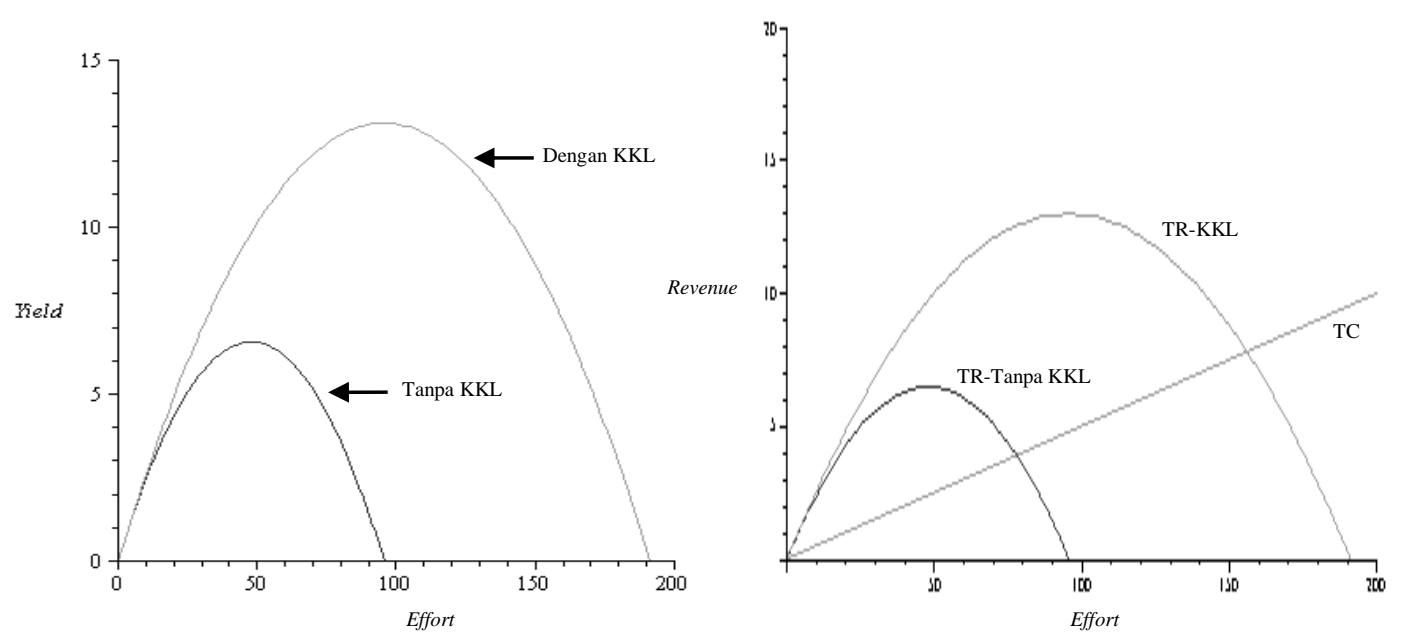

Gambar 9 Kurva yield-effort dan total revenue dengan luasan KKL $(\sigma=50 \%)$.

ningkatnya kelimpahan dan biomasa ikan. Gambar 5 sampai Gambar 9 menunjukkan bahwa dengan luasan KKL 0,1 (10\%) sampai $0,5(50 \%)$ dari total kawasan penangkapan ikan, effort tanpa KKL lebih rendah dibandingkan effort dengan adanya $\mathrm{KKL}$, atau effort tanpa KKL berada di bawah effort dengan KKL. Hal ini menunjukkan bahwa perubahan luasan $\mathrm{KKL}$ sangat mempengaruhi produksi dan effort, demikian pula pengaruhnya terhadap rente ekonomi yang dihasilkan.

Luas yang optimal untuk KKL adalah antara $15-25 \%$ (dari daerah tangkapan ikan), jika intensitas perikanan di daerah sekitarnya tidak melebihi $40 \%$ dari total biomasa yang bisa dieksploitasi (Rodwell et al. 2001 dan 2002). $\mathrm{KKL}$ mempunyai potensi untuk berperan jauh lebih besar, terhadap keberhasilan pengelolaan dan pemanfaatan SDI secara berkelanjutan, di wilayah terumbu karang dan ekosistem-ekosistem lain yang berhubungan.

\section{KESIMPULAN DAN SARAN}

\section{Kesimpulan}

Hasil penelitian menunjukkan bahwa penetapan KKL di kawasan perikanan tangkap dapat menghasilkan manfaat ekonomi lestari dengan mengurangi effort dan mengakibatkan sustainable yield dari spill over effect.

Perubahan luasan KKL dalam kondisi baseline hanya sedikit mempengaruhi effort dan produksi, namun cukup berpengaruh besar terhadap rente ekonomi yang dihasilkan.

Model bionomi dapat digunakan sebagai instrumen untuk menghasilkan indikator pengelolaan KKL yang terukur yang dapat dijadikan point referensi dalam mengendalikan input dan output dalam pengelolaan perikanan tangkap.

\section{Saran}

Penerapan KKL agar segera diikuti dengan pengelolaan yang efektif, mengingat dari analisis bionomi terlihat jelas bahwa KKL menguntungkan.

Penelitian ini hanya menggunakan parameter luasan sebagai variabel scenario (exogenous). Disarankan pada penelitian lanjut dapat menggunakan parameter biofisik lainnya dan parameter luasan bisa dijadikan variabel endogenous.

Dampak livelihood dari pengguna kawasan dalam model ini tidak secara eksplisit diakomodasi. Oleh karenanya disarankan bahwa aspek ini diteliti lebih jauh dengan mengembangkan model yang sudah ada.

Kebijakan pengelolaan KKL sebaiknya didasarkan pada science based dan ini diperlukan pemahaman yang menyeluruh kepada PEMDA setempat. Oleh karena itu komunikasi intensif kepada PEMDA mengenai hasil ilmiah ini perlu dilakukan, agar dapat digunakan sebagai bahan pengambilan kebijakan.

Masalah yang sering muncul dalam pengelolaan $\mathrm{KKL}$ adalah sustainable financing. Hasil studi ini dapat dijadikan landasan untuk menentukan baseline sustainable financing dalam pengelolaan $\mathrm{KKL}$.

\section{DAFTAR PUSTAKA}

Arnason A. 2000. Challenges for Economic Policy in Sustainable Management of Marine Natural Resources. Ecological Economics 36:223-236. 
Armstrong C. \& Reithe S. 2001. Economics of Marine Protected Areas. The Fisheries Centre, University of British Columbia, Vancouver, Canada.

Anna S. 2006. Analisis Ekonomi Kawasan Konservasi Laut: Optimisasi dan Dampak Sosial Ekonomi Pada Perikanan. Paper disampaikan pada Workshop Nasional Sosial Ekonomi Perikanan, 2-4 Agustus 2006, di FPIK IPB, Bogor.

[DKP] Dinas Kelautan dan Perikanan Kabupaten Raja Ampat, 2008. Informasi Sumber daya Kelautan dan Perikanan Kabupaten Raja Ampat. Dinas Kelautan dan Perikanan Kabupaten Raja Ampat.

[DKP] Dinas Kelautan dan Perikanan Kabupaten Raja Ampat, 2006. Atlas Sumberdaya Kelautan dan Perikanan Kabupaten Raja Ampat. Dinas Kelautan dan Perikanan Kabupaten Raja Ampat.

Fauzi, A. 2001. An overview of economic valuation techniques: $A$ highlight on information needed for their application in developing countries, in Feoli, E. \& C.E. Nauen (eds) Proceedings of the INCODEV International Workshop on Information System for Policy and Technical Support in Fisheries and Aquaculture., ACP-EU Fish. Res.Rep., (8): 135p.

Fauzi A, dan Anna S. 2005. Pemodelan Sumber Daya Perikanan dan Kelautan. Jakarta: PT.Gramedia Pustaka Utama. 343 hal.
Fauzi, A. and E. Buchary, 2002: A SocioEconomic Perspective of environmental degradation at Kepulauan Seribu National Marine Park. Coastal Management Journal Vol 30(2). 167-181

Johannes R E. 1998. Tropical marine reserves should encompass spawning aggregation sites. Parks Vol. 8 No. 2, p. 53-54.

Roberts, M.C and N.V.C. Polunin. 1993. Marine Reserves: Simple Solutions to Managing Complex Fisheries? Ambio 22, 363 368.

Roberts, M.C \& Hawkins J P. 2000. Fullyprotected marine reserves: A guide. WWF in Washington DC USA, University of York, York, UK.131 p.

Rodwell L D. Barbier E B. Roberts C M. \& McClanahan T.R. 2001. Economics of Marine Protected Areas. Published by The Fisheries Centre, University of British Columbia, Vancouver, Canada. $p$. 183-197.

Rodwell. L., E.B. Barbier., C.M Roberts., and T. R. McClanahan. 2002. A Model of Tropical Marine Reserve-Fishery Linkages. Natural Resource Modeling Vol 15(4): 453-486.

Sanchirico, J and J. Wilen. 2001. A Bioeconomics Model of Marine Reserve Creation, J. Envir. Econ. Manage. 42, 257276. 